\title{
Health status, work limitations, and return-to-work trajectories in injured workers with musculoskeletal disorders
}

\author{
Ute Bültmann · Renée-Louise Franche • \\ Sheilah Hogg-Johnson · Pierre Côté · Hyunmi Lee · \\ Colette Severin · Marjan Vidmar · Nancy Carnide
}

Received: 17 December 2006/Accepted: 22 May 2007/Published online: 7 July 2007

(C) Springer Science+Business Media B.V. 2007

\begin{abstract}
Background The purpose of this study was to describe the health status and work limitations in injured workers with musculoskeletal disorders at 1 month post-injury, stratified by return-to-work status, and to document their return-towork trajectories 6 months post-injury.

Methods A sample of 632 workers with a back or upper extremity musculoskeletal disorder, who filed a Workplace Safety and Insurance Board lost-time claim injury, participated in this prospective study. Participants were assessed at baseline (1 month post-injury) and at 6 months follow-up.

Results One month post-injury, poor physical health, high levels of depressive symptoms and high work limitations are prevalent in workers, including in those with a
\end{abstract}

\footnotetext{
U. Bültmann

National Research Centre for the Working Environment, Lerso

Parkalle 105, 2100 Copenhagen, Denmark

Present Address:

U. Bültmann ( $\square)$

Department of Health Sciences, University Medical Center Groningen, Antonius Deusinglaan 1, Building 3217, room 605, 9713 AV Groningen, The Netherlands

e-mail: u.bultmann@med.umcg.nl

R.-L. Franche · S. Hogg-Johnson · P. Côté ·

H. Lee · C. Severin · M. Vidmar · N. Carnide

Institute for Work \& Health, Toronto, Canada

R.-L. Franche · S. Hogg-Johnson · P. Côté

University of Toronto, Toronto, Canada

P. Côté

University Health Network Rehabilitation Solutions, Toronto

Western Hospital, Toronto, Canada
}

sustained first return to work. Workers with a sustained first return to work report a better health status and fewer work limitations than those who experienced a recurrence of work absence or who never returned to work. Six months post-injury, the rate of recurrence of work absence in the trajectories of injured workers who have made at least one return to work attempt is high (38\%), including the rate for workers with an initial sustained first return to work $(27 \%)$.

Conclusions There are return-to-work status specific health outcomes in injured workers. A sustained first return to work is not equivalent to a complete recovery from musculoskeletal disorders.

Keywords Health outcomes - Musculoskeletal disorders · Return to work · Work limitations · Workers' compensation

$\begin{array}{ll}\text { Abbreviations } & \\ \text { MSK } & \text { Musculoskeletal } \\ \text { RTW } & \text { Return-to-work } \\ \text { WSIB } & \text { Workplace Safety and Insurance Board } \\ \text { RTW-S } & \text { Sustained first return to work } \\ \text { RTW-R } & \text { Recurrence(s) after a first return to work } \\ \text { No RTW } & \text { No return to work } \\ \text { UE } & \text { Upper extremity } \\ \text { QuickDASH } & \text { Quick_disabilities of the arm, shoulder, and } \\ & \text { hand } \\ \text { SF-12 } & \text { Short Form-12 } \\ \text { PCS12 } & \text { Physical component summary-12 } \\ \text { MCS12 } & \text { Mental component summary-12 } \\ \text { CES-D } & \text { Center for Epidemiologic Studies } \\ & \text { Depression } \\ \text { WLQ-16 } & \text { Work Limitations Questionnaire-16 }\end{array}$




\section{Introduction}

Work-related musculoskeletal (MSK) disorders are common health problems and a major contributor to disability and costs in working populations. In Canada, MSK disorders are responsible for $10 \%$ of the short-term disability costs and $39 \%$ of the estimated long-term disability costs [1]. The natural course of low back pain and other MSK disorders is characterized by recurrent disabling symptoms and can be described as chronic-episodic [2-6]. Similarly, the trajectory of return-to-work (RTW) following a period of work absence due to MSK disorders is a complex and dynamic process, frequently involving recurrences of work absence [7, 8]. Already a decade ago, it was shown that a first return to work after an injury is frequently followed by one or more recurrences of work absence, making a focus on first return to work a limited and potentially misguiding index of RTW outcomes, and one that does not address the important issue of sustainability of return to work $[9,10]$.

Recently, Pransky et al. [7] pointed out that "despite an abundance of RTW research, the concept of RTW is often poorly defined, and there is not substantial agreement about what constitutes a successful RTW outcome." Many studies have been focused on (first) return to work as the primary outcome measure, e.g., return to work is used as an indicator for a reduction in disability-usually with the assumption that workers who return to work are completely recovered from the disabling effects of the injury [10]. However, several studies have demonstrated that workers who return to work are not fully recovered from their initial complaints or injury [10-15]. The traditional outcome measures of return to work and time lost from work do not capture important information about the burden of injury that can be shown by self-reported measures of disability and functional limitations. Hence, to obtain a complete picture of the complex RTW process, capturing the recurrences of work absence, the persistence of disability, and their consequences for work performance, it is important to use multiple outcome measures during followup. Although a few studies have addressed health outcomes, such as pain, functional status, and general health, in relation to RTW status [11, 12,14], little is known about depressive symptoms, which have been suggested to increase the total numbers of days on benefit [16] and about limitations at work in injured workers. Furthermore, it is largely unclear how injured workers "transit" in their RTW status over time. So far, we do know that a substantial proportion of workers with cumulative trauma disorders of the upper extremity [15] and compensated back pain (Côté et al., submitted) experience multiple episodes of work absence.
The purpose of this study was to describe the health status, assessed by multiple outcome measures, and work limitations, in injured workers with MSK disorders 1 month post-injury stratified by RTW status, and to document their RTW trajectories over a period of 6 months post-injury.

\section{Materials and methods}

\section{Study design}

The present study was conducted within the sampling frame of a prospective study of Ontario workers with a back or upper extremity (UE) MSK disorder, who filed a Workplace Safety and Insurance Board (WSIB) lost-time injury claim. Data was collected from two sources: selfreports of participants and WSIB administrative data. The participants were interviewed by phone at baseline (1 month post-injury), and 6 months post-injury. Participants provided information on their RTW experience, workplace, healthcare provider, insurer, and physical and mental health. From the WSIB, administrative information on sociodemographics, workplaces, and claims (e.g., site of injury, claim status, time receiving wage replacement benefits) was obtained. This information was linked to the interview data, when the participants provided written consent for linkage. Ethical approval for the study was granted by the University of Toronto's Ethics Review Board. Participants were given the option to withdraw from the study at any point and to decline data linkage of their questionnaire responses with their WSIB data. It was made explicit to the respondents that study participation would in no way affect their claim with the insurer.

Participant recruitment and final study sample

Study eligibility required participants to have a new, accepted or pending, back or UE MSK lost-time claim, be absent from work for at least 5 days within the first 14 calendar days post-injury, and be 15 years of age or older. We excluded claimants with a fracture, amputation, burn, hernia, head injury, concussion, or electrocution, those who were not able to understand or speak English, and those with a security problem, who were incarcerated or received institutional care. From January to July 2005, a computer program run on WSIB weekly files resulted in the identification of 14,555 potential participants. Eligibility assessment and recruitment were conducted in three stages: at the WSIB tracking level, at the WSIB recruiting level, and the university-based research unit level (see Fig. 1). 
Fig. 1 Recruitment procedure and flow of participants

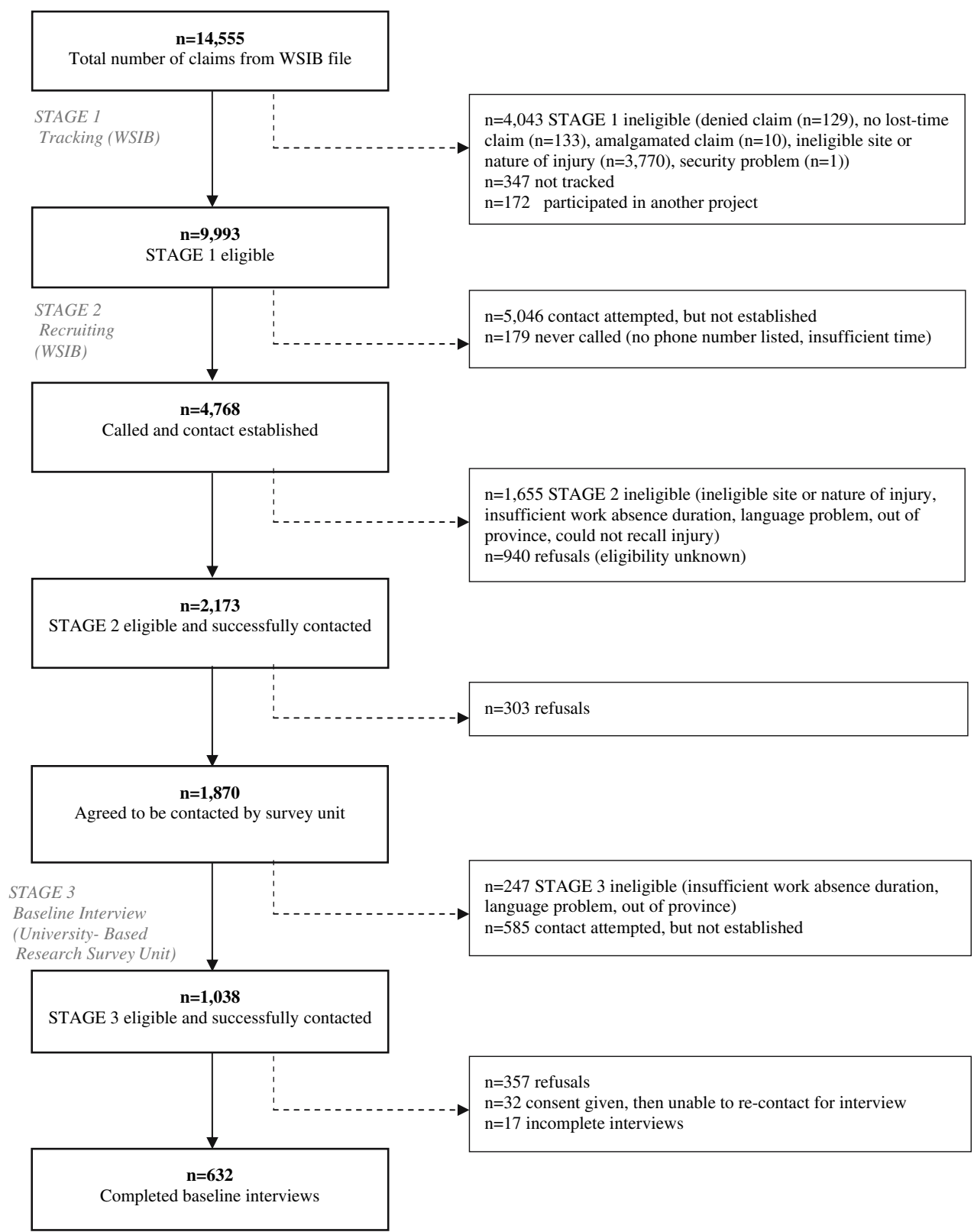

A total of 632 participants completed the baseline interview 1 month post-injury. The overall response rate was $61 \%$ (632 out of 1,038 eligible and contacted potential participants). Verbal consent for the interview data was obtained from all participants. The mean time between the date of injury and the date of interview was 29.6 days ( $S D$ 6.2; median 29 days, range 15-46 days). Approximately $98 \%$ of the participants were interviewed within 6 weeks post-injury. For the linkage with WSIB data, written consent was obtained from 479 participants, for which WSIB wage replacement data was available for 431 participants. A consent-to-linkage analysis showed that consenters ( $n=479)$ and non-consenters were similar in terms of sociodemographic, workplace, health status, and work absence variables. However, consenters were more likely to have a higher level of education, and male consenters were more likely to be older than male non-consenters (Franche et al., submitted).

\section{Definition of the RTW status}

At baseline, four mutually exclusive RTW status groups were constructed, based on the workers' responses to the following yes/no questions: "Have you gone back to work at any point since your injury (includes part-time or modified work)?" and "Are you currently working at any job right now?' The four groups were: (1) sustained first return to work $(R T W-S),(2)$ return to work with recurrence(s) of work absence and working at time of interview $(R T W-R$ working), (3) return to work with recurrence(s) of work 
absence and not working at time of interview ( $R T W-R$ not working), and (4) no return to work (No RTW). In the analyses, we collapsed the two return to work with recurrence(s) groups into one group $(R T W-R)$. RTW status was assessed at each follow-up.

Measurements: health outcomes and work limitations

\section{Pain intensity}

We used two items from the Von Korff Pain Scale [17, 18] to measure pain intensity. On a 10-point numerical rating scale $(0=$ "no pain" to $10=$ "pain as bad as could be" $)$, participants were asked to indicate their level of perceived pain from their workplace injury (1) at the present time and (2) on average in the past month.

\section{Functional status}

Functional disability associated with back pain was measured using the Roland-Morris Disability Questionnaire [19], a 24-item questionnaire assessing the presence of activity limitations. Responses to individual items (yes/no) are summed up and range from 0 (no disability) to 24 (severe disability). The score is averaged and-for a better comparison with scores of other instruments - transformed to a standardized score of 0-100 (by multiplying each averaged score by 100), with a higher score indicating greater disability. The Roland-Morris has been shown to have good psychometric properties [20-25]. In the baseline sample, the internal consistency (Cronbachs $\alpha$ ) was 0.92 .

The 11-item QuickDASH was used to assess physical function and symptoms in participants with MSK disorders of the upper limb [26]. The QuickDASH is a shortened version of the DASH Outcome Measure [27]. The items are scored from 1 to 5 . Responses to the individual items are summed, averaged, and transformed to a standardized score of 0-100, with a higher score indicating greater disability. Initial testing has shown that the QuickDASH has good psychometric properties [26]. The internal consistency in the present study was 0.90 .

When participants reported pain in both the back and UE, they completed both the Roland-Morris and the QuickDASH. For these participants, scores from each instrument were converted into a $z$-score and the highest $z$ score was used as the index of functional status. For participants completing only one measure of functional status, the $z$-score of that measure was used as the index of functional status. In addition, for those completing both measures, determination of the main pain site, i.e., back or UE, was based on the highest z-score on the Roland-Morris or the QuickDASH.

\section{General health}

The Short Form-12 (SF-12), a 12-item version of the SF36, was used to measure physical (Physical Component Summary Scale Score; PCS12) and mental (Mental Component Summary Scale Score; MCS12) health-related quality of life [28, 29]. To calculate the PCS12 and MCS12, test items are scored and transformed in an algorithm to norm-based scores with a mean of 50 and a standard deviation of 10 [29]. PCS12 and MCS12 scores range from 0 to 100 , a higher score indicating better health. The psychometric properties of the SF-12 are good: coefficients for test-retest reliability, measured over 2 weeks, are 0.89 (PCS12) and 0.76 (MCS12) [28]. Moreover, Luo et al. [30] reported good internal consistency, validity, and responsiveness in patients with low back pain. In the present study, the internal consistency was 0.89 (PCS12) and $0.86(\mathrm{MCS} 12)$ at baseline.

\section{Depressive symptoms}

The 20-item Center for Epidemiologic Studies Depression (CES-D) [31] scale was used to measure depressive symptoms. The items report the frequency of occurrence of symptoms in the past week on a 4-point rating scale ranging from "rarely or none of the time" ( $<1$ day) to " "most of the time", (5-7 days). The score ranges from 0 to 60 with a higher score denoting more depressive symptoms. CES-D scores $\geq 16$ are indicative of individuals at risk for clinical depression [31]. The internal consistency was 0.92 , measured in the baseline sample.

\section{Work limitations}

We used the 16-item version of the Work Limitations Questionnaire (WLQ-16) to assess limitations at work due to injury or associated treatment [32-35]. The WLQ-16 covers four domains: output demands (4 items), mental demands (6 items), physical demands (4 items), and time management demands (2 items). Items are scored on a 5point scale, ranging from "none of the time", to "all of the time.' The scores on the individual items are summed, averaged, and transformed to a standardized score of 0 100 , with a higher score indicative of more limitations. The internal consistency Cronbachs $\alpha$ 's were 0.82 (output demands), 0.86 (mental demands), 0.78 (physical demands), and 0.76 (time management demands) at baseline.

\section{Sociodemographics, days off work, and comorbidity}

Participants provided information on age, gender, education, living status, number of children under the age of 18 , and personal income. Information on occupational status 
was obtained from the WSIB database. One self-reported question assessed how many full days of work a participant had missed due to the injury. In addition, data on time receiving wage replacement benefits was obtained from the WSIB database. The Saskatchewan Comorbidity Scale was used to measure comorbidity (Jaroszynski et al., unpublished work). The 16/14-item (women/men) self-report scale assesses the presence and severity of health problems. Participants are instructed to indicate whether they currently have a particular health problem/disease and, if so how much it has affected their health in the last 6 months. The response options range from $1=$ "not at all" to $4=$ "severe." In the present study, two additional items pertaining to gynecological problems and pregnancy status were added for women. Responses were combined and categorized as: no comorbidity, comorbidity with no/mild effect on health, and comorbidity with moderate/severe effect on health.

\section{Statistical analyses}

Univariate statistics (means, standard deviations, frequency counts) were used to describe participants, for the total cohort and by RTW status, in terms of their baseline sociodemographics, health outcomes, and work limitations. Differences in baseline characteristics between the three RTW status groups (RTW-S, RTW-R, and No RTW) were tested using a $\chi^{2}$ test or analysis of variance. Multiple comparisons, with RTW-S as reference group, were performed with a Tukey correction. Group differences in health outcomes and work limitations, adjusted for identified covariates were tested with GLM analyses, and multiple comparisons were performed with a Bonferroni correction. To describe the RTW trajectories, we used the self-reported RTW status at baseline and 6-month follow-up. All statistical analyses were performed with SPSS 13.0 [36].

\section{Results}

Baseline characteristics and selection bias analysis

A total of 632 participants, 350 (55\%) men and $282(45 \%)$ women, completed the baseline interview 1 month postinjury. Table 1 shows the sociodemographic factors for the total sample and by RTW status at baseline. The mean age of the total cohort was 42.2 years (SD 10.8) and approximately $69 \%$ lived with a partner. The mean duration of time receiving wage replacement benefits, based on WSIB data, was 19.1 days ( $S D$ 8.9; median 20 days). Sixty-six percent of the participants were primarily experiencing back pain and $34 \%$ UE pain.
To examine a possible selection bias, we compared the cohort participants $(n=632)$ to a group of algorithm-selected potential participants $(n=3,712)$ on characteristics extracted from the WSIB database, where the algorithm mimicked the inclusion criteria of our study. ${ }^{1}$ The time frame during which their injury occurred was the same as for our study sample. This analysis showed that participants were comparable to potential participants with regards to firm size, industrial sector, and income level (Table 2). However, participants were more likely to be older and female. Women aged 40-49 were more likely to participate than women in the other age categories, and older men were more likely to participate than younger men. With respect to claim status, we compared only participants with accepted claims and available wage replacement data $(n=559)$ with potential participants, since this data is not available for participants with pending, denied or abandoned claims. Participants were more likely to have a longer duration on wage replacement benefits at 1 and 6 months post-injury and a higher rate of wage replacement re-instatement at 6 months post-injury than potential participants, suggestive of more severe work disability in our cohort.

\section{Group differences in baseline characteristics}

A total of 625 participants were categorized into one of the four RTW status groups. The remaining seven participants were working when interviewed at baseline, but not asked about recurrence(s) due to an error in a skip pattern of the questionnaire, which was subsequently corrected. At baseline (approximately 1 month post-injury), 47\% of the

\footnotetext{
${ }^{1}$ WSIB data files are consolidated and stable only at 6 months postinjury. At that time point, an algorithm mimicking our initial inclusion criteria was applied to the entire WSIB claimant population who registered a claim during the study's baseline data collection period. The algorithm mimicked the following inclusion criteria: work absence duration, site of injury, nature of injury, age. Due to the nature of WSIB data, benefit information is collected continuously only for accepted claims. In that regard, this is not a perfectly comparable group for our cohort, as our cohort also includes denied and abandoned claims. However, it remains the best comparison group available to investigate the representativeness of the cohort. In order to adjust for the absence of information on denied and abandoned claims in the WSIB files, we also applied the algorithm to the cohort. While all 632 participants met inclusion criteria at time of baseline interview, only $66 \%(n=415)$ of our cohort met the algorithm-based criteria 6 month post-injury. There are two main reasons for this. First, our inclusion criterion was registration of a lost-time claim, not its acceptance (our cohort includes denied/abandoned claims), and the algorithm could only select accepted lost-time claims. Second, our inclusion criterion was a minimum of five self-reported days of absence in the first 14 days, while the algorithm selected a minimum of 5 days on benefits during the first 14 days. This allowed for claimants who missed 5 or more days of work in the first 14 days post-injury, with no compensation, to be included in the cohort.
} 
Table 1 Baseline (1 month post-injury) sociodemographic characteristics, days off work, pain site, and comorbidity for the total study sample $(n=632)$ and by return-to-work status group ${ }^{\mathrm{a}}$

\begin{tabular}{|c|c|c|c|c|c|c|c|c|}
\hline \multirow[b]{3}{*}{ Gender } & \multirow{2}{*}{\multicolumn{2}{|c|}{$\frac{\text { Total }}{N=632}$}} & \multirow{2}{*}{\multicolumn{2}{|c|}{$\frac{\text { RTW-S }}{N=293(46.9 \%)}$}} & \multirow{2}{*}{\multicolumn{2}{|c|}{$\frac{\mathrm{RTW}-\mathrm{R}}{N=88(14.1 \%)}$}} & \multirow{2}{*}{\multicolumn{2}{|c|}{$\begin{array}{l}\text { No RTW } \\
N=244(39.0 \%)\end{array}$}} \\
\hline & & & & & & & & \\
\hline & $N$ & $(\%)$ & $N$ & $(\%)$ & $N$ & $(\%)$ & $N$ & $(\%)$ \\
\hline Female & 282 & $(44.6)$ & 123 & $(42.0)$ & 48 & $(54.5)$ & 110 & $(45.1)$ \\
\hline Male & 350 & $(55.4)$ & 170 & $(58.0)$ & 40 & $(45.5)$ & 134 & $(54.9)$ \\
\hline \multicolumn{9}{|l|}{ Age categories } \\
\hline 15-29 years & 93 & $(14.7)$ & 45 & $(15.4)$ & 9 & $(10.2)$ & 35 & $(14.4)$ \\
\hline 30-39 years & 137 & $(21.7)$ & 58 & $(19.8)$ & 29 & $(33.0)$ & 48 & $(19.8)$ \\
\hline 40-49 years & 228 & $(36.1)$ & 109 & $(37.2)$ & 31 & $(35.2)$ & 87 & $(35.8)$ \\
\hline$\geq 50$ years & 173 & $(27.4)$ & 81 & $(27.6)$ & 19 & $(21.6)$ & 73 & $(30.0)$ \\
\hline \multicolumn{9}{|l|}{ Living with/without partner } \\
\hline Living with partner & 433 & $(68.5)$ & 221 & $(75.4)$ & 54 & $(61.4)$ & 156 & $(63.9)$ \\
\hline Not living with partner & 199 & $(31.5)$ & 72 & $(24.6)$ & 34 & $(38.6)$ & 88 & $(36.1)$ \\
\hline \multicolumn{9}{|l|}{ Children under age 18} \\
\hline No children & 341 & $(54.0)$ & 158 & $(53.9)$ & 48 & $(54.5)$ & 131 & $(53.7)$ \\
\hline 1 child & 118 & $(18.7)$ & 53 & $(18.1)$ & 17 & $(19.3)$ & 47 & (19.3) \\
\hline 2 children & 118 & $(18.7)$ & 57 & $(19.5)$ & 15 & $(17.0)$ & 44 & $(18.0)$ \\
\hline$\geq 3$ children & 55 & $(8.7)$ & 25 & $(8.5)$ & 8 & $(9.1)$ & 22 & $(9.0)$ \\
\hline \multicolumn{9}{|l|}{ Education } \\
\hline Some high school & 112 & $(17.7)$ & 46 & $(15.7)$ & 16 & $(18.2)$ & 49 & $(20.1)$ \\
\hline High school completed & 177 & $(28.0)$ & 75 & $(25.6)$ & 30 & $(34.1)$ & 69 & $(28.3)$ \\
\hline Some university or college & 130 & $(20.6)$ & 70 & $(23.9)$ & 14 & $(15.9)$ & 45 & $(18.4)$ \\
\hline University/college completed & 213 & $(33.7)$ & 102 & $(34.8)$ & 28 & $(31.8)$ & 81 & (33.2) \\
\hline \multicolumn{9}{|l|}{ Occupational status $(N=479)^{\mathrm{b}}$} \\
\hline White collar & 89 & $(18.6)$ & 47 & $(20.9)$ & 13 & $(17.6)$ & 29 & $(16.4)$ \\
\hline Pink collar & 156 & $(32.6)$ & 71 & $(31.6)$ & 26 & $(35.1)$ & 58 & $(32.8)$ \\
\hline Blue collar-indoor & 99 & $(20.7)$ & 54 & $(24.0)$ & 15 & $(20.3)$ & 30 & $(16.9)$ \\
\hline Blue collar-outdoor & 68 & $(14.2)$ & 28 & $(12.4)$ & 10 & $(13.5)$ & 28 & $(15.8)$ \\
\hline Missing & 67 & $(14.0)$ & 25 & $(11.1)$ & 10 & $(13.5)$ & 32 & (18.1) \\
\hline \multicolumn{9}{|l|}{ Personal income } \\
\hline$<\$ 20,000$ & 95 & $(15.0)$ & 31 & $(10.6)$ & 12 & $(13.6)$ & 47 & (19.3) \\
\hline$\$ 20,000-39,999$ & 240 & $(38.0)$ & 111 & (37.9) & 32 & $(36.4)$ & 96 & (39.3) \\
\hline$\$ 40,000-59,999$ & 180 & $(28.5)$ & 88 & $(30.0)$ & 28 & $(31.8)$ & 64 & (26.2) \\
\hline$>\$ 60,000$ & 81 & (12.8) & 46 & (15.7) & 9 & $(10.2)$ & 25 & (10.2) \\
\hline Missing & 36 & (5.7) & 17 & (5.8) & 7 & (8.0) & 12 & (4.9) \\
\hline \multicolumn{9}{|c|}{ Number of working hours/week at the time of the injury; $n(\%)$} \\
\hline$\leq 37.5$ & 179 & $(28.3)$ & 84 & $(28.7)$ & 24 & $(27.3)$ & 69 & $(28.3)$ \\
\hline$>37.5-40.0$ & 281 & $(44.5)$ & 128 & $(43.7)$ & 40 & $(45.5)$ & 110 & $(45.1)$ \\
\hline$>40.0$ & 172 & $(27.2)$ & 81 & $(27.6)$ & 24 & $(27.3)$ & 65 & $(26.6)$ \\
\hline \multicolumn{9}{|c|}{ Duration of receiving full wage replacement benefits within first 30 days post-injury ${ }^{c}$} \\
\hline & & \multicolumn{2}{|c|}{$n=205$} & & \multicolumn{2}{|l|}{$n=67$} & \multicolumn{2}{|l|}{$n=156$} \\
\hline Days mean $(S D)$ & 19.1 & $(8.9)$ & 14.2 & $(7.1)$ & 18.7 & $(8.4)$ & 25.9 & $(6.5)$ \\
\hline Days; median & 20.0 & & 13.0 & & 19.0 & & 29.0 & \\
\hline \multicolumn{9}{|c|}{ Self-reported full days off work due to injury } \\
\hline Days mean $(S D)$ & 14.5 & $(7.1)$ & 10.5 & $(5.1)$ & 14.1 & (6.9) & 19.7 & $(6.1)$ \\
\hline Days; median & 14.0 & & 10.0 & & 13.5 & & 19 & \\
\hline \multicolumn{9}{|l|}{ Pain site; $n(\%)$} \\
\hline Back & 418 & (66.1) & 214 & (73.0) & 64 & (72.7) & 134 & (54.9) \\
\hline
\end{tabular}


Table 1 continued

\begin{tabular}{|c|c|c|c|c|c|c|c|c|}
\hline \multirow[b]{3}{*}{ Upper extremities } & \multirow{2}{*}{\multicolumn{2}{|c|}{$\frac{\text { Total }}{N=632}$}} & \multirow{2}{*}{\multicolumn{2}{|c|}{$\frac{\text { RTW-S }}{N=293(46.9 \%)}$}} & \multirow{2}{*}{\multicolumn{2}{|c|}{$\begin{array}{l}\text { RTW-R } \\
N=88(14.1 \%)\end{array}$}} & \multirow{2}{*}{\multicolumn{2}{|c|}{$\frac{\text { No RTW }}{N=244(39.0 \%)}$}} \\
\hline & & & & & & & & \\
\hline & 214 & (33.9) & 79 & $(27.0)$ & 24 & $(27.3)$ & 110 & $(45.1)$ \\
\hline \multicolumn{9}{|l|}{ Comorbidity; $n(\%)$} \\
\hline No & 513 & $(81.2)$ & 238 & $(81.2)$ & 72 & $(81.8)$ & 197 & $(80.7)$ \\
\hline Yes, with no/mild effect on health & 33 & $(5.2)$ & 16 & $(5.5)$ & 5 & $(5.7)$ & 12 & (4.9) \\
\hline Yes, with moderate/severe effect on health & 86 & (13.6) & 39 & (13.3) & 11 & (12.5) & 35 & (14.4) \\
\hline
\end{tabular}

a $N=625$ classified with regard to RTW status, $N=7$ were working at time of the baseline interview, but were not asked item regarding recurrences

b WSIB information available for participants who provided informed consent for linkage of WSIB data with questionnaire data

c $N=431$ for WSIB temporary total compensation within 30 days of accident; Missing data due to (1) no informed consent for linkage of WSIB data with questionnaire data $(N=153)$ or $(2)$ absence of data when claim was not a lost-time accepted claim $(N=48)$

participants reported a sustained first return to work, $5 \%$ a return to work with recurrence(s) of work absence and working at time of interview, almost $9 \%$ a return to work with recurrence(s) of work absence and not working at time of interview, and $39 \%$ no return to work.

With regards to gender, age, children under age 18, education, occupational status, and working hours per week at the time of the injury no statistically significant differences were observed across the three RTW groups. However, participants who had a sustained first return to work reported more often that they lived with a partner $\left(\chi^{2}=11.0, p=.004\right)$ and reported a higher personal income $\left(\chi^{2}=11.7, p=.069\right)$ than those with a recurrence or no return to work. These variables were used as covariates in subsequent analyses.

With respect to the mean duration of time receiving wage replacement benefits, based on WSIB data, significant differences were observed across all three RTW groups $(F=122.6, p=.000)$. Significant differences were also seen with self-reported full days off work due to the injury $(F=169.7, p=.0000)$. With respect to pain site, a statistically significant difference was found across the RTW groups: participants with a sustained first return to work and those who experienced a recurrence reported low back pain more often, and participants who did not return to work reported pain in the UE more often $\left(\chi^{2}=21.6\right.$, $p=<.0001)$. A total of $81 \%$ of the participants reported no comorbidity, whereas $5 \%$ reported no/mild effects on health, and $14 \%$ reported moderate/severe effects on health, with no statistically significant group differences.

Group differences in health outcomes and work limitations

Table 3 presents the adjusted (for age, gender, living status, and income level) estimated means for baseline health outcomes and work limitations by RTW status, with multiple comparison results. Participants with a sustained first return to work reported significantly less pain compared to those with a recurrence and no return to work. Moreover, they also reported significantly less pain in the past month compared to those with no return to work. In participants with back pain, those with a sustained first return to work reported significantly less functional disability compared to those with a recurrence and no return to work. In participants with UE pain, we observed that those with a sustained first return to work reported significantly less functional disability compared to those who did not return to work, but not compared to those who experienced a recurrence. With regards to physical and mental health as well as depressive symptoms, participants with a sustained first return to work reported significantly better health and fewer depressive symptoms than those with a recurrence and no return to work. It is interesting to note that high levels of depressive symptomatology, indicative of being at risk for clinical depression, were found in all participants, especially in those with a recurrence and those who did not return to work. For all outcomes, there were no significant differences between participants who experienced a recurrence and those who did not return to work. With regards to limitations at work, those with a sustained first return to work and those with a recurrence, reported limitations in all domains, but mainly for physical demands and time management demands. As expected, participants with a sustained first return to work reported significantly fewer limitations than those with a recurrence.

Attrition analysis

Six months after injury, the 632 participants who had completed the baseline interview were approached again to complete the follow-up interview. Overall, 446 participants, $238(53 \%)$ men and 208 (47\%) women, completed the follow-up interview (retention rate of 70.6\%). Reasons for non-response in the follow-up interview were "unable to contact'" $(n=92)$, "avoided contact'" $(n=49)$, and 
Table 2 Comparison of baseline study participants with algorithm-selected potential study participants

\begin{tabular}{|c|c|c|}
\hline Variable & $\begin{array}{l}\text { Full baseline } \\
\text { cohort }(n=632)\end{array}$ & $\begin{array}{l}\text { Algorithm-selected potential } \\
\text { participants }(n=3,712)\end{array}$ \\
\hline \multicolumn{3}{|l|}{ Gender, $n(\%)$} \\
\hline Female & $282(44.6)$ & $1,365(36.8)$ \\
\hline Male & $350(55.4)$ & $2,347(63.2)$ \\
\hline Age at baseline interview, mean $(S D)$ (median) & $42.2(10.8)(43)$ & 40.3 (11.3) (40.7) \\
\hline \multicolumn{3}{|l|}{ Gender $\times$ age at baseline interview, $n(\%)$} \\
\hline Females: $15-29$ years & $40(6.3)$ & $262(7.1)$ \\
\hline Females: $30-39$ years & $59(9.3)$ & 348 (9.4) \\
\hline Females: $40-49$ years & $109(17.2)$ & $428(11.5)$ \\
\hline Females: $\geq 50$ years & $74(11.7)$ & $327(8.8)$ \\
\hline Males: $15-29$ years & $53(8.4)$ & $524(14.1)$ \\
\hline Males: $30-39$ years & $78(12.3)$ & $630(17.0)$ \\
\hline Males: $40-49$ years & $119(18.8)$ & $714(19.2)$ \\
\hline Males: $\geq 50$ years & $99(15.7)$ & 479 (12.9) \\
\hline \multicolumn{3}{|l|}{ Firm size, $n(\%)$} \\
\hline$<20$ employees & $58(9.2)$ & $335(9.0)$ \\
\hline 20-99 employees & $100(15.8)$ & $680(18.3)$ \\
\hline 100-999 employees & $190(30.1)$ & $1,166(31.4)$ \\
\hline$\geq 1,000$ employees & $150(23.7)$ & 769 (20.7) \\
\hline Schedule 2 & $134(21.2)$ & $761(20.5)$ \\
\hline \multicolumn{3}{|l|}{ Industrial sector, $n(\%)$} \\
\hline Automotive, manufacturing, steel & $109(17.2)$ & $875(23.6)$ \\
\hline Service & $127(20.1)$ & $812(21.9)$ \\
\hline Education, municipal, Schedule $2^{\mathrm{a}}$ & $146(23.1)$ & $817(22.0)$ \\
\hline Healthcare & $85(13.4)$ & 425 (11.4) \\
\hline Transportation & $55(8.7)$ & $333(9.0)$ \\
\hline Chemical/processing, electrical, food & $31(4.9)$ & $212(5.7)$ \\
\hline Construction & $14(2.2)$ & $154(4.1)$ \\
\hline Agriculture, forest, pulp and paper, mining & $15(2.4)$ & $83(2.2)$ \\
\hline Unknown & $50(7.9)$ & $1(0.0)$ \\
\hline \multicolumn{3}{|l|}{ Occupational status, $n(\%)^{\mathrm{b}}$} \\
\hline White collar & $109(18.7)$ & $624(16.8)$ \\
\hline Pink collar & $209(35.9)$ & $1,112(30.0)$ \\
\hline Blue collar-indoor & $132(22.7)$ & $1,026(27.6)$ \\
\hline Blue collar-outdoor & $86(14.8)$ & $631(17.0)$ \\
\hline Missing & $45(7.7)$ & $319(8.6)$ \\
\hline \multicolumn{3}{|l|}{ Weekly earnings in tertiles, $n(\%)$} \\
\hline$\leq \$ 447.68$ & $116(18.4)$ & $819(22.1)$ \\
\hline$\$ 447.68-\leq \$ 880.00$ & $281(44.5)$ & $1,890(50.9)$ \\
\hline$\geq \$ 880.00$ & $157(24.8)$ & $978(26.3)$ \\
\hline Missing & $78(12.3)$ & $25(0.7)$ \\
\hline $\begin{array}{l}\text { Duration of time receiving wage replacement } \\
\text { benefits ( } 30 \text { days post-injury), mean }(S D)(\text { median })^{\mathrm{c}}\end{array}$ & $20.6(9.0)(25)$ & $15.9(9.4)(13)$ \\
\hline $\begin{array}{l}\text { Duration of time receiving wage replacement } \\
\text { benefits (180 days post-injury), mean }(S D) \text { (median) }\end{array}$ & $58.7(57.2)(33)$ & $37.6(50.2)(14)$ \\
\hline \multicolumn{3}{|l|}{$\begin{array}{l}\text { Occurrence of re-instatement of wage replacement } \\
\text { benefits ( } 30 \text { days post-injury), } n(\%)^{\mathrm{c}}\end{array}$} \\
\hline No & $507(90.7)$ & $3,481(93.8)$ \\
\hline Yes & $52(9.3)$ & $231(6.2)$ \\
\hline
\end{tabular}


Table 2 continued

\begin{tabular}{lcr}
\hline Variable & $\begin{array}{l}\text { Full baseline } \\
\text { cohort }(n=632)\end{array}$ & $\begin{array}{c}\text { Algorithm-se } \\
\text { participants }( \\
\end{array}$
\end{tabular}

a Schedule 2 firms do not operate under the collective liability insurance principle, and, as such, are individually responsible for the full cost of the injury/illness claims filed by their workers. Schedule 2 employers include federal, provincial and municipal governments, railways, airlines, shipping, and telephone companies

b Data on the full baseline cohort is restricted to participants with accepted claims $(n=582)$

c Data on the full baseline cohort is restricted to participants with accepted claims and available wage replacement data 30 days post-injury $(n=559)$

d Data on the full baseline cohort is restricted to participants with accepted claims and available wage replacement data 180 days post-injury $(n=561)$

Note: Italics-The main differences between the full baseline cohort and the algorithm-selected potential participants

Table 3 Estimated means (95\% confidence intervals, CI) of baseline ( 1 month post-injury) health outcomes and limitations at work by returnto-work status group $(N=625)$, adjusted for age, gender, living status, and personal income

\begin{tabular}{|c|c|c|c|c|c|}
\hline & \multirow{3}{*}{$\begin{array}{l}\frac{\mathrm{RTW}_{-} \mathrm{a}}{N=293(46.9 \%)} \\
\frac{\text { Estimated mean }(95 \% \mathrm{CI})}{}\end{array}$} & \multirow{2}{*}{\multicolumn{2}{|c|}{$\frac{\mathrm{RTW}-\mathrm{R}}{N=88(14.1 \%)}$}} & \multirow{2}{*}{\multicolumn{2}{|c|}{$\begin{array}{l}\text { No RTW } \\
N=244(39.0 \%)\end{array}$}} \\
\hline & & & & & \\
\hline & & Estimated mean $(95 \% \mathrm{CI})$ & $p$ & Estimated mean $(95 \% \mathrm{CI})$ & $p$ \\
\hline \multicolumn{6}{|l|}{ Perceived pain } \\
\hline \multicolumn{6}{|l|}{ Range $0-10$} \\
\hline Pain at time of interview & $3.84(3.54-4.13)$ & $5.19(4.64-5.73)$ & .000 & $5.94(5.62-6.27)$ & .000 \\
\hline Pain in the past month & $8.45(8.25-9.13)$ & $8.78(8.40-9.16)$ & .421 & $8.90(8.68-9.13)$ & .014 \\
\hline \multicolumn{6}{|l|}{ Roland Morris } \\
\hline Range $0-100 ; N=418$ & $52.73(49.29-56.17)$ & $68.14(61.75-74.54)$ & .000 & $75.66(71.30-80.03)$ & .000 \\
\hline \multicolumn{6}{|l|}{ Quick DASH } \\
\hline Range $0-100 ; N=214$ & $47.58(42.61-52.55)$ & $54.94(46.01-63.87)$ & .469 & $63.15(58.98-67.33)$ & .000 \\
\hline \multicolumn{6}{|l|}{ Physical SF-12 } \\
\hline Range $0-100$ & $37.03(35.98-38.09)$ & $32.75(30.80-34.69)$ & .000 & $31.63(30.47-32.78)$ & .000 \\
\hline \multicolumn{6}{|l|}{ Mental SF-12 } \\
\hline Range $0-100$ & $48.55(47.18-49.91)$ & $44.40(41.88-46.92)$ & .014 & $45.58(44.08-47.07)$ & .013 \\
\hline \multicolumn{6}{|l|}{ Depressive symptoms } \\
\hline CES-D; Range 0-60 & $13.16(11.74-14.59)$ & $18.15(15.53-20.78)$ & .003 & $18.70(17.14-20.26)$ & .000 \\
\hline \multicolumn{6}{|l|}{ Work limitations } \\
\hline \multicolumn{6}{|l|}{ Range $0-100$} \\
\hline Physical demands & $46.00(42.79-49.22)$ & $62.81(56.80-68.82)$ & .000 & n.a. & \\
\hline Mental demands & $17.12(14.70-19.55)$ & $29.41(24.88-33.95)$ & .000 & n.a. & \\
\hline Output demands & $18.65(15.95-21.35)$ & $35.59(30.56-40.61)$ & .000 & n.a. & \\
\hline Time management & $41.83(38.43-45.23)$ & $61.90(55.61-68.20)$ & .000 & n.a. & \\
\hline
\end{tabular}

a The RTW-S group is the reference group for the multiple comparisons 


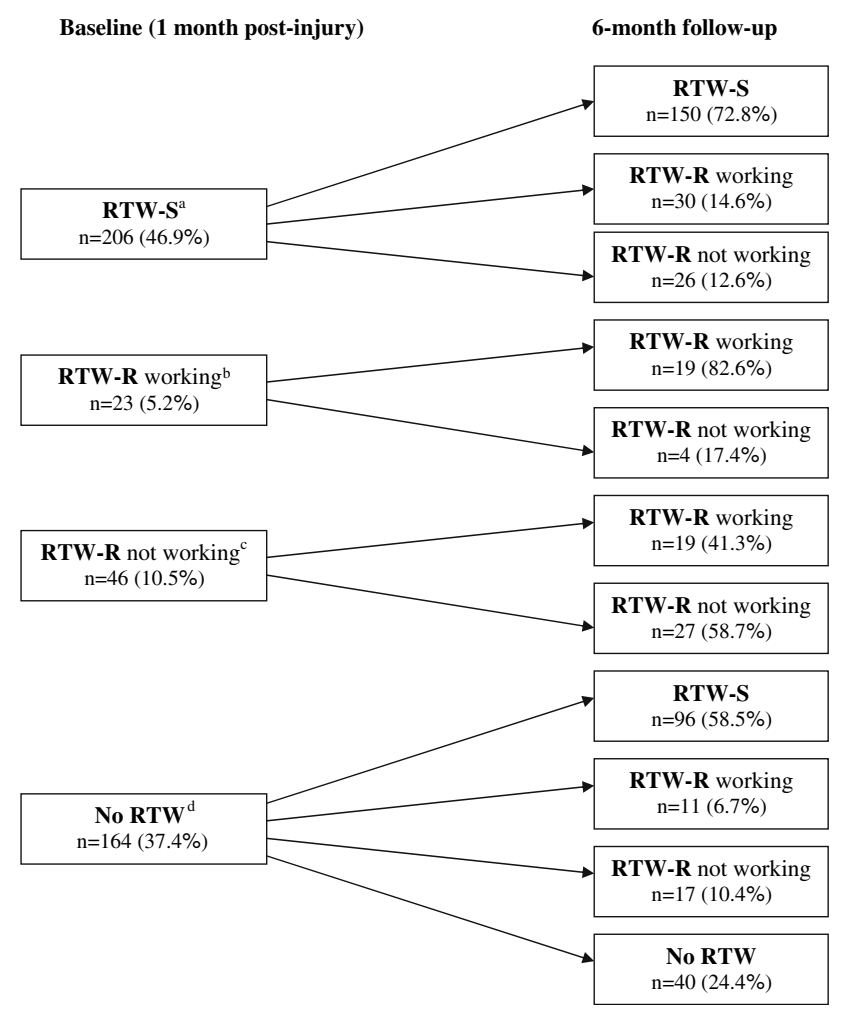

Fig. 2 Return-to-work trajectories based on self-reported return-towork status at baseline (1 month post-injury) and 6-month follow-up $(n=439)$. ${ }^{\mathrm{a}} \mathrm{RTW}-\mathrm{S}$, sustained first return to work; ${ }^{\mathrm{b}} \mathrm{RTW}-\mathrm{R}$ working, return to work with recurrence(s) of work absence and working at time of interview; ${ }^{\mathrm{c}} \mathrm{RTW}-\mathrm{R}$ not working, return to work with recurrence(s) of work absence and not working at time of interview; ${ }^{\mathrm{d}}$ No RTW, no return to work

"refused to participate" $(n=45)$. An attrition analysis, comparing respondents $(n=446)$ of the 6-month interview with non-respondents $(n=186)$, revealed that nonrespondents were more likely to be younger, to work longer hours at the time of injury, and to specify "back" as their primary pain site. Moreover, male non-respondents tended to be younger than male respondents, whereas in females differences in age were not statistically significant. Otherwise, non-respondents did not differ significantly with respect to other sociodemographic, workplace, health status, and work absence variables tested, including time receiving wage replacement benefits, re-instatement of wage replacement benefits 6 month post-injury, self-reported work absence duration 1 month post-injury, and claim status. Full details of the attrition bias analysis have been reported elsewhere (Franche et al., submitted).

\section{RTW trajectories from baseline to 6 month follow-up}

Figure 2 shows the RTW trajectories for 439 participants, based on self-reported RTW status at baseline and 6 month follow-up. The majority (73\%) of workers with a sustained first return to work at baseline were still at work 6 months later. However, $27 \%$ had experienced at least one recurrence during that time period. All participants who experienced a recurrence remained, by definition, in this group. Of those participants who had not returned to work at baseline, $59 \%$ had a sustained first return to work 6 months later, $17 \%$ had made a RTW attempt with a recurrence, and $24 \%$ were still off work 6 months post-injury. Six months post-injury, the rate of recurrences of work absence in workers who had made at least one RTW attempt was $38 \%$ [ $n=153$ recurrences $/(n=439$ minus $n=40$ with no RTW attempt)].

\section{Discussion}

The findings of this cohort study suggest the presence of a pattern in baseline health states and work limitations specific to RTW status, 1 month post-injury. Workers with a sustained first return to work reported less pain, less functional disability, better physical and mental health, fewer depressive symptoms, and fewer work limitations compared to those who experienced a recurrence of work absence or who never returned to work. The study adds to the literature by demonstrating that depressive symptoms and limitations at work are prevalent in workers 1 month post-injury, including in those with a sustained first return to work. A substantial rate of recurrences of work absence over 6 months was found (38\%), even in workers who had initially made a sustained first return to work at baseline $(27 \%)$. Moreover, of those workers who did not return to work at baseline, $17 \%$ attempted to return and experienced a recurrence within 6 months of the injury, and 24\% were still off work at 6 months post-injury.

Our findings are consistent with previous research suggesting that a return to work does not translate into a complete recovery from a MSK disorder [11, 12, 14, 15]. For example, in a study among 205 workers with MSK injury, Evanoff et al. [14] found that $88 \%$ of the workers had returned to work (with $83 \%$ working at full duty) at 6 month follow-up, and of these $24 \%$ reported continuing disability due to the injury (including $20 \%$ of those working at full duty). In our study, participants with a sustained first return to work at 1 month post-injury had SF-12 physical and mental health subscales scores below the healthy population average of 50 [29], and high levels of work limitations, specifically for physical demands and time management demands. Thus, the results suggest that many workers, while back at work, still have health problems and experience difficulties in meeting their work demands. Furthermore, the importance of measuring multiple health outcomes, in particular depressive symptoms, was shown by the high levels of depressive symptoms, 
indicative of being at risk for clinical depression, in injured workers suffering from MSK disorders, particularly in those who experienced a recurrence and those who did not return to work. Our finding of high levels of depressive symptoms in injured workers is in line with earlier studies showing that depressive symptoms are prevalent in MSKinjured workers $[37,38]$ and highlights the need to address and examine the mental health of workers suffering a workplace injury. Moreover, 6 months post-injury we found a high rate of recurrences of work absence (38\%) in workers who had made at least one RTW attempt, which is consistent with studies suggesting that there is considerable movement in and out of work after the first return to work [15 Côté et al., submitted]. In a study among 1,321 US workers who filed a workers compensation claim for back pain, Côté et al. (submitted) observed that $23 \%$ and $30 \%$ of the workers, 6 and 12 months post-onset of back pain, respectively, experienced multiple work absences.

When interpreting the results, the following methodological issues must be considered. Though reasonable for a study among claimants, the overall participation rate of $61 \%$ raises the question of selective participation, which may have biased the results. However, the cohort was shown to be representative of the most comparable claimant group with regards to basic demographic and workplace variables, but not with regards to duration of time receiving wage replacement benefits and rates of wage replacement re-instatement, suggesting the presence of more severe disability in the cohort. Hence, the generalizability of the results remains limited with respect to workers with less severe work disability. More importantly, the rates of self-reported recurrence of work absence may be inflated in our cohort.

A related issue concerns the loss-to-follow-up of $29 \%$. The attrition analysis demonstrated that non-respondents and respondents were similar with regards to time receiving wage replacement benefits, the occurrence of re-instatement of wage replacement benefits, and self-reported work absence duration. Non-respondents were younger males, worked longer hours, and were more likely to specify " 'back' as their primary pain site compared to respondents.

Future research should further explore the relationship between recurrence(s) of work absence, health outcomes, and work limitations over an extended period of time. We found that workers who experienced a recurrence after a first return to work clearly report more health problems and work limitations than those with a sustained first return to work, and their health status is often comparable to workers who do not return to work. Our trajectory analyses were based on a 6 months time window and it was not yet possible to examine multiple recurrences and their effects on health outcomes and work limitations over a longer period of time. However, 12 month follow-up data will make such analyses possible in the future. Moreover, we have to examine important and meaningful changes in health outcomes and work limitations between baseline and follow-up across the possible RTW trajectories [39], and also study them in relation to a broad range of factors (e.g., RTW interventions, disability management strategies) that might have influenced the RTW process and the outcomes considered. Finally, future research should identify early prognostic factors of the trajectories, particularly focusing on the "problematic" trajectories (recurrences and persistent work absence), so that guidance for an optimal reintegration or for recurrence prevention can be provided.

To conclude, the results of this prospective study suggest that workers who had a sustained first return to work report a better health status and fewer work limitations than those who experienced a recurrence after a first return to work or who did not return to work. However, it is also demonstrated that a return to work is not equivalent to a complete recovery from MSK disorders. Workers who had a sustained first return to work still reported meaningful health limitations, as compared to the general population and significant work limitations. Given the considerable impact of disability on worker health and costs for the workers, employers, and society, the findings highlight the importance of considering multiple health outcomes, including depressive symptoms and work limitations, when studying the complex process of return to work and when developing RTW interventions and disability management strategies.

Acknowledgements This project was funded by a research grant provided by the Workplace Safety and Insurance Board (Ontario) and by the Work Disability Prevention CIHR Training Program of the University of Sherbrooke, Quebec, Canada.

\section{References}

1. Health Canada (1998). Economic burden of illness in Canada. Ottawa: Health Canada.

2. Cassidy, J. D., Côté, P., Carroll, L. J., \& Kristman, V. (2005). Incidence and course of low back pain episodes in the general population. Spine, 30, 2817-2823.

3. Wasiak, R., Verma, S., Pransky, G., \& Webster, B. (2004). Risk factors for recurrent episodes of care and work disability: Case of low back pain. Journal of Occupational and Environmental Medicine, 46, 68-76.

4. Hestbaek, L., Leboeuf-Yde, C., Engberg, M., Lauritzen, T., Bruun, N. H., \& Manniche, C. (2003). The course of low back pain in a general population. Results from a 5-year prospective study. Journal of Manipulative and Physiological Therapeutics, 26, 213-219.

5. Picavet, H. S., \& Schouten, J. S. (2003). Musculoskeletal pain in the Netherlands: Prevalences, consequences and risk groups, the DMC(3)-study. Pain, 102, 167-178.

6. Croft, P. R., Macfarlane, G. J., Papageorgiou, A. C., Thomas, E., \& Silman, A. J. (1998). Outcome of low back pain in general practice: A prospective study. British Medical Journal, 316, $1356-1359$. 
7. Pransky, G., Gatchel, R., Linton, S. J., \& Loisel, P. (2005). Improving return to work research. Journal of Occupational Rehabilitation, 15, 453-457.

8. Frank, J., Sinclair, S., Hogg-Johnson, S., Shannon, H., Bombardier, C., Beaton, D., \& Cole, D. (1998). Preventing disability from work-related low-back pain. New evidence gives new hopeif we can just get all the players onside. Canadian Medical Association Journal, 158, 1625-1631.

9. Butler, R. J., Johnson, W. G., \& Baldwin, M. L. (1995). Managing work disability: Why first return to work is not a measure of success. Industrial and Labor Relations Review, 48, 452-469.

10. Baldwin, M. L., Johnson, W. G., \& Butler, R. J. (1996). The error of using returns-to-work to measure the outcomes of health care. American Journal of Industrial Medicine, 29, 632-641.

11. Lötters, F., Hogg-Johnson, S., \& Burdorf, A. (2005). Health status, its perceptions, and effect on return to work and recurrent sick leave. Spine, 30, 1086-1092.

12. Lötters, F., Meerding, W. J., \& Burdorf, A. (2005). Reduced productivity after sickness absence due to musculoskeletal disorders and its relation to health outcomes. Scandinavian Journal of Work, Environment and Health, 31, 367-374.

13. Pransky, G., Benjamin, K., Hill-Fotouhi, C., Fletcher, K. E., Himmelstein, J., \& Katz, J. N. (2002). Work-related outcomes in occupational low back pain: A multidimensional analysis. Spine, 27, 864-870.

14. Evanoff, B., Abedin, S., Grayson, D., Dale, A. M., Wolf, L., \& Bohr, P. (2002). Is disability underreported following work injury? Journal of Occupational Rehabilitation, 12, 139-150.

15. Baldwin, M. L., \& Butler, R. J. (2006). Upper extremity disorders in the workplace: Costs and outcomes beyond the first return to work. Journal of Occupational Rehabilitation, 16, 296-316.

16. Lötters F., Franche, R. L., Hogg-Johnson, S., Burdorf, A., \& Pole, J. D. (2006). The prognostic value of depressive symptoms, fearavoidance, and self-efficacy for duration of lost-time benefits in workers with musculoskeletal disorders. Occupational and Environmental Medicine, 63, 794-801.

17. VonKorff, M., Ormel, J., Keefe, F. J., \& Dworkin, S. F. (1992). Grading the severity of chronic pain. Pain, 50, 133-149.

18. VonKorff, M., Jensen, M. P., \& Karoly, P. (2000). Assessing global pain severity by self-report in clinical and health services research. Spine, 25, 3140-3151.

19. Roland, M., \& Morris, R. (1983). A study of the natural history of back pain. Part I: Development of a reliable and sensitive measure of disability in low-back pain. Spine, 8, 141-144.

20. Leclaire, R., Blier, F., Fortin L., \& Proulx R. (1997). A crosssectional study comparing the Oswestry and Roland-Morris Functional Disability scales in two populations of patients with low back pain of different levels of severity. Spine, 22, 68-71.

21. Deyo, R. A. (1986). Comparative validity of the sickness impact profile and shorter scales for functional assessment in low-back pain. Spine, 11, 951-954.

22. Hsieh, C. Y., Phillips, R. B., Adams, A. H., \& Pope, M. H. (1992). Functional outcomes of low back pain: Comparison of four treatment groups in a randomized controlled trial. Journal of Manipulative and Physiological Therapeutics, 15, 4-9.

23. Kopec, J. A., \& Esdaile, J. M. (1995). Functional disability scales for back pain. Spine, 20, 1943-1949.
24. Stratford, P. W., Binkley, J., Solomon, P., Finch, E., Gill, C., \& Moreland, J. (1996). Defining the minimum level of detectable change for the Roland-Morris questionnaire. Physical Therapy, 76, 359-365.

25. Beurskens, A. J., de Vet, H. C., \& Koke, A. J. (1996). Responsiveness of functional status in low back pain: A comparison of different instruments. Pain, 65, 71-76.

26. Beaton, D. E., Wright, J. G., Katz, J. N., The Upper Extremity Collaborative Group (2005). Development of the QuickDASH: Comparison of three item-reduction approaches. The Journal of Bone \& Joint Surgery American Volume, 87, 1038-1046.

27. Hudak, P. L., Amadio, P. C., \& Bombardier, C. (1996). Development of an upper extremity outcome measure: The DASH (disabilities of the arm, shoulder and hand). The Upper Extremity Collaborative Group (UECG). American Journal of Industrial Medicine, 29, 602-608.

28. Ware, J. Jr., Kosinski, M., \& Keller, S. D. (1996). A 12-Item Short-Form Health Survey: Construction of scales and preliminary tests of reliability and validity. Medical Care, 34, 220 233.

29. Ware, J. Jr., Kosinski, M., \& Keller, S. D. (2002). SF-12: How to score the SF-12 Physical and Mental Health Summary scales. Lincoln: Quality Metric Inc.

30. Luo, X., Lynn, G. M., Kakouras, I., Edwards, C. L., Pietrobon, R., Richardson, W., \& Hey, L. (2003). Reliability, validity, and responsiveness of the short form 12-item survey (SF-12) in patients with back pain. Spine, 28, 1739-1745.

31. Radloff, L. S. (1977). The CES-D Scale: A self-report depression scale for research in the general population. Applied Psychological Measurement, 1, 385-401.

32. Lerner, D., Amick, B. C. III, Rogers, W. H., Malspeis, S., Bungay, K., \& Cynn, D. (2001). The Work Limitations Questionnaire. Medical Care, 39, 72-85.

33. Lerner, D., Amick, B. C. III, Lee, J. C., Rooney, T., Rogers, W. H., Chang, H., \& Berndt, E. R. (2003). Relationship of employeereported work limitations to work productivity. Medical Care, 41, 649-659.

34. Lerner, D., Adler, D. A., Chang, H., Berndt, E. R., Irish, J. T., Lapitsky, L., Hood, M. Y., Reed, J., \& Rogers, W. H. (2004). The clinical and occupational correlates of work productivity loss among employed patients with depression. Journal of Occupational and Environmental Medicine, 46, S46-S55.

35. Beaton, D. E., \& Kennedy, C. A. (2005). Beyond return to work: Testing a measure of at-work disability in workers with musculoskeletal pain. Quality of Life Research, 14, 1869-1879.

36. SPSS for Windows (2005). Rel. 13.0. Chicago: SPSS Inc.

37. Dersh, J., Gatchel, R. J., Polatin, P., \& Mayer T. (2002). Prevalence of psychiatric disorders in patients with chronic work-related musculoskeletal pain disability. Journal of Occupational and Environmental Medicine, 44, 459-468.

38. Keogh, J. P., Nuwayhid, I., Gordon J. L., \& Gucer, P. (2000). The impact of occupational injury on injured worker and family: Outcomes of upper extremity cumulative trauma disorders in Maryland workers. American Journal of Industrial Medicine, 38, 498-506.

39. Beaton, D. E., Bombardier, C., Katz, J. N., \& Wright, J. G. (2001). A taxonomy for responsiveness. Journal of Clinical Epidemiology, 54, 1204-1217. 